\title{
The Tolerance of Chromium (VI) by Delftia acidovorans
}

\author{
$\underline{\text { Hongyan Zuo }}^{1}$ and Hailiang Dong ${ }^{2}$
}

1. Department of geology \& environmental earth science, Oxford, Ohio, USA

${ }^{2}$. Department of geology \& environmental earth science, Oxford, Ohio, USA

Delftia acidovorans, formly called comamonas acidovorans, is an aerobic, non-fastidious, non-fermentative gram-negative bacillus, which is famous for producing solid gold from soluble gold (Johnston et al., 2013). However, Delftia acidovorans, owing to their ability to survive from $\mathrm{Au}^{3+}$, may offer opportunities for bioreduction of heavy metals. Delftia acidovorans are cultured, harvested and rinsed before introduced into $\mathrm{K}_{2} \mathrm{CrO}_{4}$ solution.

A full-scale experiment was designed to determine the ability of Delftia acidovorans to reduce $\mathrm{Cr}^{6+}$ under optimal growth conditions. Cells in the exponential phase were combined with oxic, filter sterilized stock solution of potassium chromate, $\mathrm{K}_{2} \mathrm{CrO}_{4}$, to final $\mathrm{Cr}^{6+}$ concentrations of $0,0.2,0.4,0.90$, or $1.80 \mathrm{mM}$ in $50 \mathrm{~mL}$ centrifuge tubes. For each $\mathrm{Cr}^{6+}$ concentration, a contrast without cells was set up. 96 hours were given to the full-scale bioreduction experiment (Singh et al. 2013).

Aqueous $\mathrm{Cr}^{6+}$ concentration was measured with spectroscopy at $540 \mathrm{~nm}$ using the 1,5-diphenyl carbazide (DPC) colorimetric method. The bioreduction of $\mathrm{Cr}^{6+}$ are tested as given in Fig.1. The reduction extent decreases with increasing in $\mathrm{Cr}^{6+}$ concentration, varying from $30 \%$ to $99 \%$. The highest reduction extent was achieved at $0.2 \mathrm{mM}$ concentration. With $\mathrm{Cr}^{6+}$ concentration of $1.8 \mathrm{mM}$, the reduction was only achieved $30 \%$, illustrating Delftia acidovorans couldn't reduce $\mathrm{Cr}^{6+}$ any more.

To investigate the effect of $\mathrm{Cr}^{6+}$ on Delftia acidovorans, microscopic analysis were applied. Bacteria were embedded in resin after series of fixation, dehydration and infiltration. Ultrathin-sections were collected onto $\mathrm{Cu}$-grids for transmitted electron microscopic analysis (Fig.2). The TEM photograph doesn't show changes of cells after exposure to $\mathrm{Cr}^{6+}$. Most of cells still maintained good shape, indicating high tolerance of $\mathrm{Cr}$ and $\mathrm{Cr}^{6+}$ acting as an extracellular electron acceptor. 
References:

[1] Cheng, Y. et al, Environ. Sci. Technol. 44 (2010), p. 6357.

[2] Johnston, C.W. et al, Nat Chem Biol 9 (2013), p. 241.

[3] Singh, R. et al, Geochimica et Cosmochimica Acta 148 (2015), p. 442.

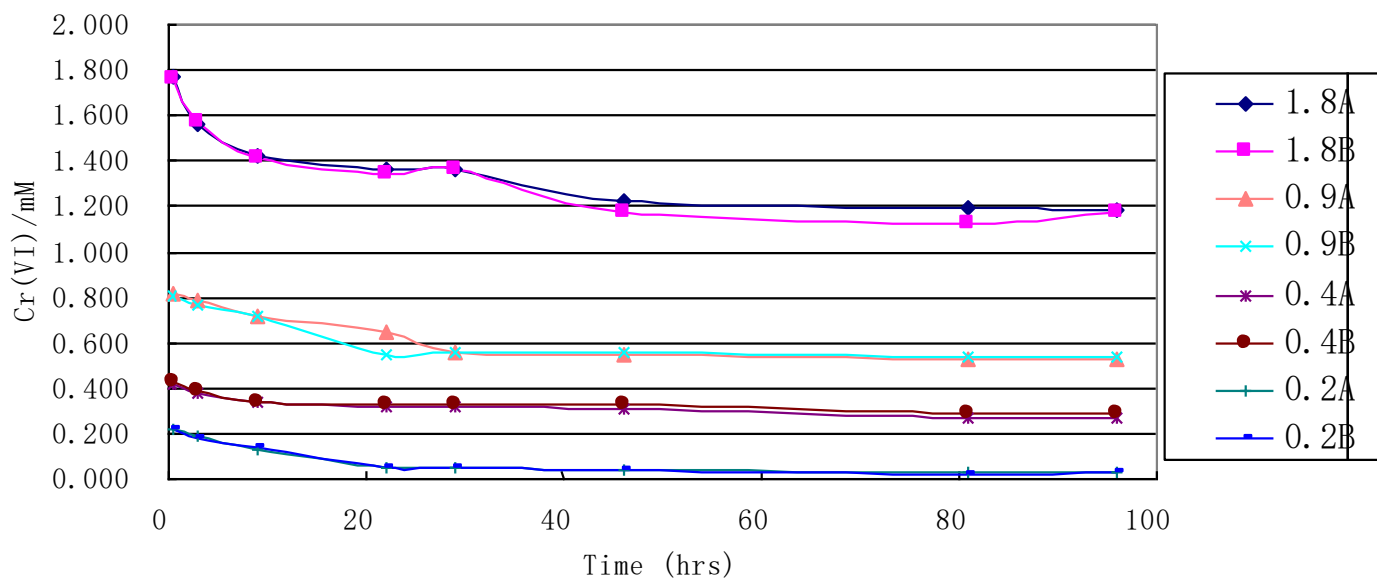

Figure 1. Bioreduction of $\mathrm{Cr}^{6+}$ by Delftia acidovorans at various concentrations. $99 \%$ reduction was achieved at concentration $0.2 \mathrm{mM}$, but bioreduction extents were low at $0.4 \mathrm{mM}, 0.9 \mathrm{mM}$ and $1.8 \mathrm{mM}$.

Figure 2. TEM image of Delftia acidovorans treated with $1.8 \mathrm{mM} \mathrm{Cr}^{6+}$, showing no significant change in the shape of cells.

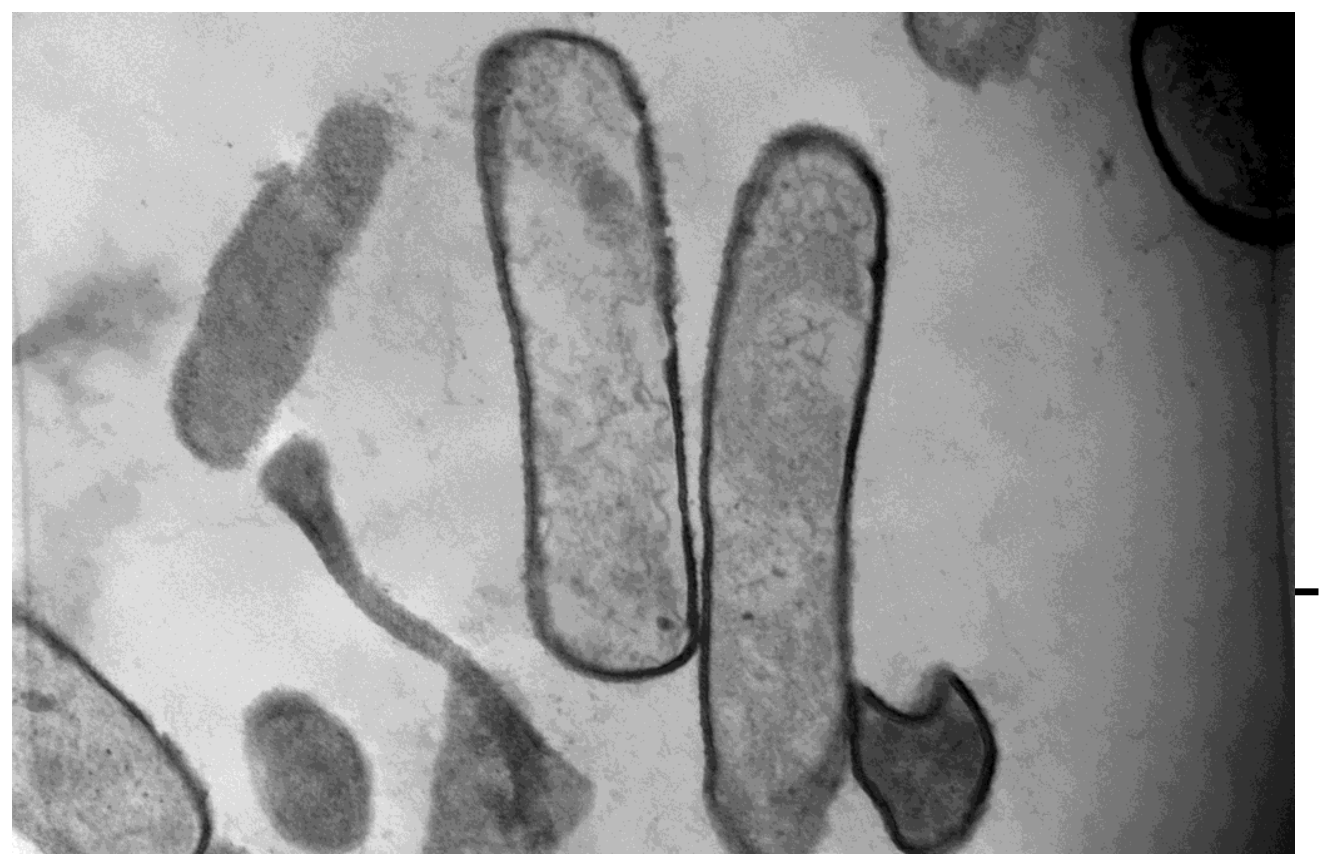

